This is an electronic reprint of the original article. This reprint may differ from the original in pagination and typographic detail.

\author{
Author(s): Kankaanpää, Irja; Tiihonen, Päivi; Ahonen, Jarmo; Koskinen, Jussi; Tilus, Tero; Sivula, \\ Henna
}

Title: $\quad$ Legacy system evolution - A comparative study of modernisation and replacement initiation factors

Year: $\quad 2007$

Version:

Please cite the original version:

Kankaanpää, I., Tiihonen, P., Ahonen, J., Koskinen, J., Tilus, T., \& Sivula, H. (2007). Legacy system evolution - A comparative study of modernisation and replacement initiation factors. In Proceedings of the 9th International Conference on Enterprise Information Systems (ICEIS 2007) (pp. 280-287). INSTICC Press.

https://doi.org/10.5220/0002378102800287

All material supplied via JYX is protected by copyright and other intellectual property rights, and duplication or sale of all or part of any of the repository collections is not permitted, except that material may be duplicated by you for your research use or educational purposes in electronic or print form. You must obtain permission for any other use. Electronic or print copies may not be offered, whether for sale or otherwise to anyone who is not an authorised user. 


\title{
LEGACY SYSTEM EVOLUTION A Comparative Study of Modernisation and Replacement Initiation Factors
}

\author{
Irja Kankaanpää \\ Information Technology Research Institute, University of Jyväskylä, Mattilanniemi 2, Jyväskylä, Finland \\ irja.kankaanpaa@titu.jyu.fi \\ Päivi Tiihonen \\ Jyväskylä University of Applied Science, Piippukatu 3, Jyväskylä, Finland \\ paivi.tiihonen@jamk.fi \\ Jarmo J. Ahonen \\ Department of Computer Science, University of Kuopio, Kuopio, Finland \\ jarmo.ahonen@uku.fi \\ Jussi Koskinen \\ Department of Computer Science and Information Systems, University of Jyväskylä, Jyväskylä, Finland \\ koskinen@cs.jyu.fi
}

Tero Tilus, Henna Sivula

tero@tilus.net,henna.sivula@gmail.com

Keywords: $\quad$ Legacy system evolution, evolution initiation, decision making, initiation factor.

Abstract: Decisions regarding information system evolution strategy become topical as the organisation's information systems age and start to approach the end of their life cycle. An interview study was conducted in order to compare factors influencing modernisation and replacement initiation. System age, obsolete technology and high operation or maintenance costs were identified as triggers for both modernisation and replacement projects. The results show that the most prevalent individual reason for modernisation initiative is business development. Common initiation factors for replacement projects were end of vendor support and system's inability to respond to organisation's business needs.

\section{INTRODUCTION}

Continuous evolution is necessary in order to maintain a system's ability to respond to the requirements of its environment (Lehman 1998). When a system ages and conventional maintenance faces increasing difficulties with system up-dates the organisation often faces a "legacy dilemma" (Bennett 1995). A system with a long lifetime often contains accumulated business critical data yet preserving its functionality as such would require extensive use of resources and face difficulties due to obsolete technology (Bennett 1995).

There are three strategies to tackle a legacy system: 1) continuing maintenance despite of possible complications, 2) replacing the legacy system with a new system, or 3) modernising it (Bennett 1995, Seacord et al. 2003, p. 8-10). Modernization and replacement are significant economical investments with wide range of organisational effects. Consequently, evolution decisions are of great importance. In practice, the 
assessment of potential evolution options is challenging and decisions are often made informally and largely based on intuition (Saarelainen et al. 2006).

The aim of this study is to compare replacement and modernisation projects in order to provide an understanding of the factors influencing evolution initiation. A comparative study is important because when the differences and similarities of evolution types are known they can be taken into consideration in evolution planning and decision processes. The term evolution initiative refers to "a formally established and organized effort to evolve a system" (Bergey et al. 1997). Here, the term initiation factor refers to the decision basis and the reasons that trigger evolution activities.

\section{EVOLUTION OPTIONS AND DECISION MAKING}

In the past, several decision frameworks and models have been developed to systemise legacy system management and decision making. These include SABA - a decision model for legacy systems (Bennett et al. 1999), Renaissance (Warren and Ransom 2002), A decision framework for Legacy System Management (De Lucia et al. 2001), and Enterprise Framework for the Disciplined Evolution of Legacy Systems (Bergey et al. 1997). All these models emphasise the fact that legacy system decisions should include consideration of a number of factors and that the decision process should be rather formal in order to assure the success of system evolution. It has been proposed that the essential elements influencing legacy system evolution initiative are organisation, project, legacy system, target system, systems engineering, software engineering and technologies (Bergey et al. 1997).

Modernisation aims at improving the existing system to correspond with the requirements of its environment. It involves such radical modification that it cannot be considered as regular maintenance (Seacord et al. 2003, p. 9). Despite the significant improvements, a considerable proportion of the legacy system is conserved in the modernisation (Seacord et al. 2003, p. 9). Aversano et al. (2004) propose that prior to modernisation decision the technical and the business value of the existing system should be assessed. Koskinen et al. (2005) list twenty decision criteria influencing modernisation decision making, the ten most important criteria being: system usability, end of technological support, changes in business processes, maintenance costs, system correctness, system efficiency, expected remaining system lifetime, size of required changes, application domain expertise of maintainers, and delocalized system logic.

Replacement refers to an activity as a result of which a legacy system is replaced with another system providing the same functionalities (Warren and Ransom 2002). The replacing system can be purchased as an off-the-shelf application (Seacord 2003, p. 10) or it can be a result of a redevelopment project (Seacord 2003, p. 10, Bisbal et al. 1999). Bandor (2006) suggests that software selection process often focuses on the system functionality while ignoring the intangible factors related to the use and organisational influences of the system, and system management and operation related risks.

\section{RESEARCH METHODS}

The goal of the study was to compare two evolution types, i.e. modernisation and replacement, with respect to evolution initiation triggers. Therefore, it was relevant to collect empirical evidence on the topic. A qualitative research approach was chosen for it was desired to produce new information on the topic and not only to verify the results of previous research. For this purpose, semi-structured interview was considered as the most suitable data collection method (see Seaman 1999). Interview topics were selected and questions formulated based on a literature survey.

A set of pre-requirements were defined for acceptable projects for the interviews. The selection criteria were: 1) the project fitted either the modernisation or the replacement definition presented earlier, 2) the project was completed, and 3) a new or modernised system had been implemented in the organisation by the time of the interview. Also, an interview could relate to one evolution project only.

\subsection{Data Acquisition}

Data was acquired with phone interviews. Randomly picked organisations were contacted and inquired whether there had been suitable modernisation or replacement projects in the organisation's past (between years 2000 and 2005). If the response was positive, a key person involved in the project was contacted and requested an interview. The suitability of projects was assessed with the key person before 
the interview. If there had been more than one project that fitted the given criteria it was negotiated with the key person which project would be best suited to for discussion.

The person interviewed was most commonly the person with the deepest involvement or knowledge about the selected project. Prior to the interview, the interviewees were sent a list of the topics that were to be covered in the interview so that they could refresh their memory on the project and check documents or other data sources if necessary.

Data collection took place between autumn 2004 and autumn 2005. A total of 60 interviews were gained but all of them could not be used in the analysis for the following reasons: the project did not meet with the pre-requirements; or the project was a borderline case between the definitions of modernisation and replacement. These interviews were excluded from the analysis. The final material sample consists of 29 interviews from which 14 concerned modernisation and 15 replacement projects. Data was collected from 28 organisations, including both private companies and public organisations, and from 29 evolution projects within. One person was interviewed per project. One organisation yielded two suitable projects and thus the number of projects (and interviews) is higher than the number of organisations.

Most of the interviewees were upper or middle level managers in data administration. The sample also included IT development executives and other IT personnel. The study focused on user organisations and, consequently, system suppliers were excluded.

\subsection{Data Analysis}

Interviews were recorded by the permission of the interviewee and then transcribed. Data collection was closed when the material was saturated, i.e. new cases did not bring new information on the topic. In data analysis, classification by theme, type, and content breakdown were used. Before the analysis the material was read through several times in order to gain familiarity with it and to identify features that describe the material in general. The material was coded by theme in order to increase the fluency of handling. After the theme classification, the material was classified according to the frequency of response types in order to increase the comparability of the results.

\subsection{Reliability of the Results}

The reliability of the results was assured by using two researchers to analyse the material. They were not connected to the organisations and approached the material from an outsider's perspective. It was noted for that the reliability of the results could be weakened by the fact that the material was relatively heterogeneous, i.e. it consisted of different types and sizes of organisations and information systems. However, the responses were fairly homogenous in both evolution types. This indicates that the diversity in target organisations and systems have not undermined the reliability of the results.

The use of semi-structured interview provided a possibility to acquire in-depth information on the same topic from a variety of interviewees. The issues and viewpoints the interviewees brought up in addition to the pre-designed questions were relevant to the topic and added depth to the material. The reliability of the results could have been improved with additional quantitative data collection.

\section{RESULTS}

In the following, the results on evolution initiation comparison are reported. Citations ${ }^{1}$ from the interviews are included in the text in order to clarify the results. The proportion of the appearance of each factor with respect to the total amount of projects is given in brackets (number of appearance / total amount). Abbreviation " $\mathrm{R}$ " is used for replacement and "M" for modernisation.

A total of 15 initiation factors were identified in the study. Some of these appeared in both modernisation and replacement projects, while some were evolution type specific. Factors influencing both modernisation and replacement initiation are system age, obsolete technology and high operation or maintenance costs. Identified replacement specific initiation factors were end of vendor support, need to unify disintegrated systems and scattered data, need for a system compatible with organisation's other systems, software or hardware, and to follow organisation's IT strategy or the prevailing IT trends within the industry. Modernisation specific initiation triggers were the desire to develop organisation's business or business processes, the requirements presented by a business

\footnotetext{
${ }^{1}$ Citations have been translated from Finnish to English by the author.
} 
partner, responding to customer needs, legislation changes, and competitive advantage.

Table 1 summarises the initiation reasons and the number of their occurrence in replacement (column "R") and modernisation (column "M") projects. The number or occurrence presents the total number of projects where a presented factor appeared.

Table 1: Reasons for evolution initiation.

\begin{tabular}{|l|c|c|}
\hline Reason for evolution initiation & R & M \\
\hline System age & 9 & 5 \\
\hline Obsolete technology & 3 & 4 \\
\hline High maintenance or operation costs & 1 & 2 \\
\hline Maintenance difficult or not possible & 1 & 3 \\
\hline End of vendor support & 7 & - \\
\hline Incompliance with business needs & 7 & - \\
\hline Disintegrated systems and scattered data & 3 & - \\
\hline Incompatibility with other systems & 3 & - \\
\hline Incompliance with IT strategy & 2 & - \\
\hline IT trends in the field of industry & 1 & - \\
\hline Business or business process development & - & 7 \\
\hline Customer needs & - & 2 \\
\hline Business partner requirements & - & 1 \\
\hline Change of legislation & - & 1 \\
\hline Competitive advance & - & 1 \\
\hline
\end{tabular}

\subsection{Replacement Initiation}

The results suggest that replacement initiation is triggered by ten factors. These factors and their distribution throughout the replacement projects is depicted in Table 2, where R\# denotes replacement project and $\mathrm{x}$ indicates the appearance of initiating factor in a project. Column $\mathrm{T}^{\mathrm{R}}$ gives the total number of initiation factors' appearance across the replacement projects.

Three factors appeared significantly more frequently than the others: the system age (9/15), the end of vendor support (7/15), and the system's inability to respond to company's current business needs (7/15). Often these three major reasons appeared together or combined with other factors. (R7): "The system was mainly from the year 1985 and then further developed. Its basic structure was nearly 20 years old ... operations had changed significantly during that time and business requirements had changed so much that it was decided to renew the system."

In almost half of the replacement projects (7/15), the reason for acquiring a new system was the legacy system supplier that had stopped or had announced the termination of system updates, maintenance or technical support. Typically, the vendor had informed the customer that development of the system would be discontinued. In R5, R11 and
R12, the existing system was not compatible with other systems in its operational environment, with new operating systems or up-dated hardware. In the following, an interviewee (R5) describes a project where both of these factors were present: "... we had a very old, about 10 years old, information system in use and we were in a situation that we could not really get updates for it and it was not compatible with these new operating systems any more. So in that situation we had to renew the system."

In R4, R9 and R12, the legacy system consisted of interoperating sub-systems and problems with scattered data arose. The goal was to unify separate systems by replacing them with a single ERP system that would store all data in one location. An interviewee (R4) concludes: “...when there are various small systems and their maintenance costs are fairly high we aimed at [getting them] within one system. On the other hand we were thinking about the transparency of customer data, and that we were transferring the same data in so many places, so that was one reason why we wanted to get rid of those separate systems."

In addition to old age and disintegrated systems, IT trends in the field of industry encouraged system replacement (R12): Well, it [system] was aged and it consisted of separate systems and at some point we should have changed it anyway ... and what I have heard is that those [companies] who used the same systems, they have had quite a strong changing wave going on."

Organisation's IT strategy guided the decision making in two cases. In R12, the system was completely rewritten in order to comply with new architecture and operating system requirements defined in the IT strategy. In R4, according to organisation's IT strategy all systems were to be united and, hence, individual systems were integrated into one organisation wide ERP system.

\subsection{Modernisation Initiation}

The results suggest that modernisation initiation is influenced by nine factors. From these three types of modernisation initiatives can be identified: business development driven modernisation, legacy system The largest individual modernisation trigger was the desire to develop the organisation's business or business processes (7/14). It was typical that the weaknesses of the legacy system were acknowledged and action was taken in order to improve related operations.

Modernisation activities were considered as a natural part of organisation's operations and they took place in regular intervals (M11): "This project, 
we called it 'the development of IT environment for better business process support'. ... the whole IT environment and architecture was developed. It supports business processes and business objectives better. ... one can say that it is an endless [process] but now [in this project] the basic improvements have been done."

In one case, where modernisation was seen as an enabler of organisational development, it was anticipated to provide competitive advance. The motive for modernisation was to be the first organisation in the national markets to use new technology (M12): "Yes, it has reference value if we are the first ones to do something." In another case, the prevailing IT trends within the industry were regularly reviewed and assessed from business development perspective (M5):

"I belong to a national data administration group and we meet fairly regularly and discuss about the state of the art of software development in our line of business."

In four modernisation projects the initiative originated solely from business development motives (M4, M12) or as response to external pressure (M6, M14). In M6, legislation had changed and required rapid changes in the system. In M14, modernisation was initiated by the change request of an important business partner and responding to it was perceived as an opportunity for system improvement to better respond to customer needs and for business development.

The results indicate that legacy system related factors form the largest group of modernisation initiation reasons. Old age (6/14), obsolete technology (5/14) and impossible maintenance (3/14) were typically mentioned. Economical factors accompanied obsolete technology. High operation costs (2/14) were additional motivators. In extreme cases, old age (M3, M9) or obsolete technology (M7) was the only reason for modernisation.

The third identified modernisation initiation type includes both technical and business reasons: system was old and did not serve the user organisation as well as in the past (M5), system was old and did not respond to new customer needs (M1), maintenance was not possible and organisation wanted to develop its business operations by modernising the existing system (M11), or maintenance was nearly impossible due to obsolete technology and system

Table 2: Reasons for replacement initiation.

\begin{tabular}{|l|c|c|c|c|c|c|c|c|c|c|c|c|c|c|c|c}
\hline Initiation factors & R1 & R2 & R3 & R4 & R5 & R6 & R7 & R8 & R9 & R10 & R11 & R12 & R13 & R14 & R15 & $\mathbf{T}^{\mathbf{R}}$ \\
\hline System age & $\mathrm{x}$ & & $\mathrm{x}$ & $\mathrm{x}$ & $\mathrm{x}$ & $\mathrm{x}$ & $\mathrm{x}$ & & $\mathrm{x}$ & & & $\mathrm{x}$ & & & $\mathrm{x}$ & 9 \\
\hline Incompliance with business needs & $\mathrm{x}$ & & $\mathrm{x}$ & & & $\mathrm{x}$ & $\mathrm{x}$ & & $\mathrm{x}$ & $\mathrm{x}$ & & & & $\mathrm{x}$ & & 7 \\
\hline End of vendor support & $\mathrm{x}$ & & & & $\mathrm{x}$ & & & $\mathrm{x}$ & $\mathrm{x}$ & & & $\mathrm{x}$ & & $\mathrm{x}$ & $\mathrm{x}$ & 7 \\
\hline Obsolete technology & & & & & & & & $\mathrm{x}$ & & & $\mathrm{x}$ & & $\mathrm{x}$ & & & 3 \\
\hline Incompatibility with other systems & & & & & $\mathrm{x}$ & & & & & & $\mathrm{x}$ & $\mathrm{x}$ & & & & 3 \\
\hline Disintegrated systems and scattered data & & & & $\mathrm{x}$ & & & & & $\mathrm{x}$ & & & $\mathrm{x}$ & & & & 3 \\
\hline Incompliance with IT strategy & & $\mathrm{x}$ & & $\mathrm{x}$ & & & & & & & & & & & & 2 \\
\hline IT trends in the field of industry & & & & & & & & & & & & $\mathrm{x}$ & & & & 1 \\
\hline Difficult maintenance & & $\mathrm{x}$ & & & & & & & & & & & & & & 1 \\
\hline High maintenance costs & & & & $\mathrm{x}$ & & & & & & & & & & & & 1 \\
\hline
\end{tabular}

Table 3: Reasons for modernisation initiation.

\begin{tabular}{|l|c|c|c|c|c|c|c|c|c|c|c|c|c|c|c|}
\hline Initiating factor & M1 & M2 & M3 & M4 & M5 & M6 & M7 & M8 & M9 & M10 & M11 & M12 & M13 & M14 & T$^{\text {M }}$ \\
\hline $\begin{array}{l}\text { Business or business process } \\
\text { development }\end{array}$ & & & & $\mathrm{x}$ & $\mathrm{x}$ & & & & & $\mathrm{x}$ & $\mathrm{x}$ & $\mathrm{x}$ & $\mathrm{x}$ & $\mathrm{x}$ & 7 \\
\hline System age & $\mathrm{x}$ & & $\mathrm{x}$ & & $\mathrm{x}$ & & & & $\mathrm{x}$ & & & & & & 4 \\
\hline Obsolete technology & & $\mathrm{x}$ & & & & & $\mathrm{x}$ & $\mathrm{x}$ & & & & & $\mathrm{x}$ & & 4 \\
\hline Maintenance not possible & & $\mathrm{x}$ & & & & & & $\mathrm{x}$ & & & & & & & 2 \\
\hline High operation costs & $\mathrm{x}$ & & & & & & & & & & & & & $\mathrm{x}$ & 2 \\
\hline Customer needs & & & & & & & & & & & & & & $\mathrm{x}$ & 1 \\
\hline Business partner requirements & & & & & & & & & & & & $\mathrm{x}$ & & & 1 \\
\hline Change of legislation & & & & & & & & & & & & & & & \\
\hline Competitive advance
\end{tabular}


was modernised in order to better supported business processes and objectives (M13).

The distribution of initiating factors throughout the modernisation projects is depicted in Table 3 , where M\# denotes modernisation project and $\mathrm{x}$ indicates the appearance of a factor in the left hand side column in a project. Column $\mathrm{T}^{\mathrm{M}}$ gives the total number of initiation factors across the modernisation projects.

\section{DISCUSSION}

The reasons behind replacement and modernisation initiatives were noticeably similar but varied in nuances. Legacy system related factors proposed in earlier studies (see e.g. Aversano et al. 2004, Bergey et al. 1997), i.e. system age, obsolete technology, or difficult and costly maintenance, influenced evolution initiation in both project types.

A separating factor concerning evolution strategy selection was the degree of evolution initiative anticipation. Organisations that decided to modernise their legacy system wanted to develop their business processes. They were, in general, aware of IT trends in their business line and launched modernisation in order to develop their business. The interviewees were not directly asked about their organisation's business perspective, yet it was mentioned as an important factor in half of the interviews. Thus, strategic business planning as management activity (see Bergey et al. 1997) was a central element. On the contrary, interviewees from organisations that had chosen replacement as an evolution strategy did not express the desire for business development. Instead, replacement was a reaction to the vendor's announcement of ending system support or to the system's inability to support organisation's business operations. This would suggest that a system management related risk appeared real (see Bandor 2006) and caused action. It is proposed that modernisation took place as a result of proactive situation assessment while replacement was a reaction to a change in organisation's internal or external environment. The reasons behind this phenomenon require further research.

The results show that legacy system replacement and modernisation differ from each other with respect to vendor influence on evolution initiation. Nearly half of the replacement projects were initiated because the system supplier had given up system development or support. However, in modernisation projects, vendor's actions did not influence evolution initiation. It is concluded that organisations that decide to replace legacy systems are more dependent on system suppliers than organisations that choose modernisation.

When compared to the earlier findings, it can be noticed that there is clear divergence between initiation factors although similarities exist, too. Table 4 lists the decision criteria reported by Koskinen et al. (2005), which are in the text denoted with $\mathrm{D}$, and the findings of this study, denoted with $\mathrm{M}^{\mathrm{IF}}$ (modernisation initiation factors) and $\mathrm{R}^{\mathrm{IF}}$ (replacement initiation factors) in a descending order of importance. An interesting finding was that system usability, which was listed as the most

Table 4: Comparison of evolution initiation criteria.

\begin{tabular}{|l|l|l|l|}
\hline No. & $\begin{array}{l}\text { Modernization decision criteria (D) } \\
\text { (Koskinen et al. 2005) }\end{array}$ & $\begin{array}{l}\text { Modernisation initiation factors } \\
\left(\mathbf{M}^{\mathbf{I F}}\right)\end{array}$ & $\begin{array}{l}\text { Replacement initiation factors } \\
\left(\mathbf{R}^{\mathrm{IF}}\right)\end{array}$ \\
\hline 1. & System usability & Business development & System age \\
\hline 2. & End of technological support & System age & End of vendor support \\
\hline 3. & Changes in business processes & Obsolete technology & Incompliance with business needs \\
\hline 4. & Maintenance costs & Maintenance not possible & Obsolete technology \\
\hline 5. & System correctness & High maintenance costs & $\begin{array}{l}\text { Disintegrated systems and scattered } \\
\text { data }\end{array}$ \\
\hline 6. & System efficiency & Customer needs & Incompatibility with other systems \\
\hline 7. & Expected remaining system lifetime & Business partner requirements & Incompliance with IT strategy \\
\hline 8. & Size of required changes & Change of legislation & IT trends in field of industry \\
\hline 9. & Application domain expertise & Competitive advance & High maintenance costs \\
\hline 10. & Delocalized system logic & & Maintenance difficult \\
\hline$\ldots$ & $\ldots$ & & \\
\hline 15. & System age & & \\
\hline 16. & Changes in business environment & & \\
\hline
\end{tabular}


important modernisation decision criteria, did not occur among the evolution initiation factors of found in this study. An explanation for this phenomenon was not found and would require further research.

Another observation is that the modernisation decision criteria reported by Koskinen et al. (2005) correspond to replacement initiation factors better than modernisation triggers found in this study. Correlation for all but one replacement initiation factor, i.e. end of vendor support $\left(\mathrm{R}^{\mathrm{IF}} 2\right)$, exists: $\mathrm{R}^{\mathrm{IF}}$ $1=\mathrm{D} 15, \mathrm{R}^{\mathrm{IF}} 3$ and $\mathrm{R}^{\mathrm{IF}} 7=\mathrm{D} 3, \mathrm{R}^{\mathrm{IF}} 4=\mathrm{D} 2, \mathrm{R}^{\mathrm{IF}} 5$ and $\mathrm{R}^{\mathrm{IF}} 6=\mathrm{D} 5, \mathrm{R}^{\mathrm{IF}} 8=\mathrm{D} 16, \mathrm{R}^{\mathrm{IF}} 9=\mathrm{D} 4$, and $\mathrm{R}^{\mathrm{IF}} 10=\mathrm{D} 7$. $\mathrm{R}^{\mathrm{IF}} 5$ and $\mathrm{R}^{\mathrm{IF}} 6$ correspond to system efficiency (D6) because they led to inefficient system use in studied organisations. It should be noted that D2 refers to general technology changes and, hence, it should not be mixed with $\mathrm{R}^{\mathrm{IF}} 2$.

Six of the identified modernisation initiation factors match with the previously presented criteria. The following correlations exist: $\mathrm{D} 2=\mathrm{M}^{\mathrm{IF}} 3$, D4 = $\mathrm{M}^{\mathrm{IF}} 5$, D7 $=\mathrm{M}^{\mathrm{IF}} 4$, D15 $=\mathrm{M}^{\mathrm{IF}}$ 2, and $\mathrm{D} 16=\mathrm{M}^{\mathrm{IF}} 6$, $\mathrm{M}^{\mathrm{IF}}$ 7. New factors, not appearing in the list by Koskinen et al. (2005), are business or business process development objective $\left(\mathrm{M}^{\mathrm{IF}} 1\right)$, end of vendor support $\left(\mathrm{R}^{\mathrm{IF}} 2\right)$, and competitive advance $\left(\mathrm{M}^{\mathrm{IF}} 10\right)$.

The amount of factors influencing evolution initiation decision is significantly smaller than given before (see Koskinen et al. 2005). The results strengthen the previous findings of the importance of engaging both business and technical aspects in evolution decision making (see Aversano et al. 2004, Bergey et al. 1997).

\section{SUMMARY}

The aim of this study was to compare replacement and modernisation projects with respect to the reasons that initiate evolution activities in order to provide evidence on their differences and similarities to support evolution planning and decision processes. The differences and similarities were mapped with an empirical study where data administration managers, IT development executives and other IT personnel from 29 evolution projects were interviewed.

The results confirm the previously suggested modernisation criteria but challenge the order of their importance. The findings question the importance of system usability, previously claimed to the most important modernisation decision criteria. New factors complementing earlier findings are business or business process development objective, end of vendor support, and gaining competitive advantage.

System age, obsolete technology and high operation or maintenance costs were identified as triggers in both evolution types. The most common initiation factors in replacement projects were system age, end of vendor support, and system's incompliance with the organisation's business needs. The most common reasons for modernisation were the desire to develop organisation's business or business processes, system age, and obsolete technology.

\section{ACKNOWLEDGEMENTS}

This work has been carried out in ITRI (Information Technology Research Institute) and financially supported by TEKES (Finnish Funding Agency for Technology and Innovation).

\section{REFERENCES}

Aversano, L., Esposito, R., Mallardo, T. and Tortorella, M., 2004. Supporting Decisions on the Adoption of Re-engineering Technologies. In CSMR'04, 8ht

European Conference on Software Maintenance and Reengineering. IEEE Computer Society, 95-104

Bandor, M. S., 2006. Quantitative Methods for Software Selection and Evaluation, Technical Note, CMU/SEI2006-TN-026. Retrieved November 15, 2006 from Carnegie Mellon University, Software Engineering Institute Web site: http://www.sei.cmu.edu/ publications/documents/06.reports/06tn026.html

Bennett, K., 1995. Legacy Systems: Coping with Success. IEEE Software, 12 (1), 19-23.

Bennett, K., Ramage, M. and Munro, M., 1999. Decision Model for Legacy Systems. IEE Proceedings Software 146 (3), 153-159.

Bergey, J. K., Northrop, L. M. and Smith, D. B., 1997. Enterprise Framework for the Disciplined Evolution of Legacy Systems, Technical Report, CMU/SEI-97TR-007, ESC-TR-97-007, Retrieved November 15, 2006 from Carnegie Mellon University, Software Engineering Institute Web site: http://www.sei.cmu. edu/publications/documents/97.reports/97tr007/97tr00 7abstract.html

Bisbal, J., Lawless, D., Wu, B. and Grimson J., 1999. Legacy Information Systems: Issues and Directions. IEEE Software, 16 (5), 103-111.

De Lucia, A., Fasolino, A.R. and Pompella, E., 2001. A Decisional Framework for Legacy System Management, In ICSM'01, International Conference on Software Maintenance, IEEE, 642-651.

Koskinen, J., Ahonen, J.J., Sivula, H., Tilus, T., Lintinen, H. and Kankaanpää, I., 2005. Software Modernization 
Decision Criteria: An Empirical Study, In CSMR'05, 9th European Conference on Software Maintenance and Reengineering. IEEE Computer Society, 324-331.

Lehman, M. M., Perry, D. E. and Ramil, J. F., 1998. Implications of Evolution Metrics on Software Maintenance. In International Conference on Software. Maintenance. IEEE Computer Society, 208217.

Saarelainen M., Ahonen, J.J., Lintinen, H., Koskinen, J., Kankaanpää, I., Sivula, H., Juutilainen, P. and Tilus, T., 2006. Software Modernization and Replacement Decision Making in Industry: A Qualitative Study. In EASE'06, 10th International Conference on Evaluation and Assessment in Software Engineering. Kitchenham, B.A., Brereton, P., Turner, M., and Charters, S. (eds.), Retrieved December 5, 2006 from BCS eWIC database.

Seacord, R. C., Plakosh, D. and Lewis G. A., 2003. Modernizing Legacy Systems - Software Technologies, Engineering Processes and Business Practices. Addison-Wesley, Boston, MA.

Seaman, C. B., 1999. Qualitative Methods in Empirical Studies of Software Engineering, IEEE Transactions on Software Engineering, 25 (4), 557-572.

Warren, I. and Ransom, J., 2002. Renaissance: A Method to Support Software System Evolution. In COMPSAC'02, $26^{\text {th }}$ Annual International Computer Software and Applications Conference. IEEE, 415420. 